\title{
Influence of Micro-arc Oxidation Coatings on Corrosion Performances of AZ80 cast alloy
}

\author{
Yuna Xue ${ }^{1,3, *}$, Xin Pang ${ }^{2, *}$, Bailing Jiang ${ }^{1}$, Hamid Jahed ${ }^{3}$ \\ ${ }^{1}$ School of Materials Science and Engineering, Xi'an University of Technology, No.5 Jinhua South \\ Road, Xi'an 710048, China \\ ${ }^{2}$ CanmetMATERIALS, Natural Resources Canada, 183 Longwood Road South, Hamilton, ON L8P \\ 0A5, Canada \\ ${ }^{3}$ Department of Mechanical \& Mechatronics Engineering, University of Waterloo, 200 University \\ Avenue West, Waterloo, ON N2L 3G1, Canada \\ *E-mail: xynlina@gmail.com, xin.pang@canada.ca
}

doi: $10.20964 / 2018.08 .38$

Received: 27 April 2018 / Accepted: 31 May 2018 / Published: 5 July 2018

To enhance the corrosion performance of cast AZ80 alloy, micro-arc oxidation (MAO) coating was synthesized at various processing current densities in a basic silicate-fluoride solution. The microstructure, composition, corrosion performance and Mott-Schottky characteristics of MAO coatings at different processing current densities were investigated using various microscopic characterization and electrochemical methods. It was found that a thinner $(5.04 \mu \mathrm{m})$ MAO coating produced at the low processing current density obtained a more uniform and smaller discharge pores morphology and higher fluoride content compared to the other coatings produced at higher current densities. The open-circuit potential, corrosion current density and polarization resistance values of this coating were $-1.28 \mathrm{~V}$ vs. $\mathrm{Ag} / \mathrm{AgCl}$ electrode, $0.00589 \mu \mathrm{A} / \mathrm{cm}^{2}$ and $1.53 \times 10^{6} \Omega \cdot \mathrm{cm}^{2}$ in $3.5 \mathrm{wt} . \%$ $\mathrm{NaCl}$, respectively. After the Mott-Schottky test, the analysis of the coating showed that the uncoated and MAO coated AZ80 alloy exhibited p-type semiconductor characteristics. For the MAO coated specimens, the coating synthesized at the lower applied current density showed lower acceptor concentration and highly negative flat band potential. These features are associated with the reduced reactivity and improved corrosion resistance of this new MAO coating.

Keywords: Micro-arc oxidation; electrochemical kinetic parameters; Semi-conducing property; AZ80 cast alloy

\section{$\underline{\text { FULL TEXT }}$}


(C) 2018 The Authors. Published by ESG (www.electrochemsci.org). This article is an open access article distributed under the terms and conditions of the Creative Commons Attribution license (http://creativecommons.org/licenses/by/4.0/). 